\title{
Special Issue: Earthquake Engineering and Structural Dynamics
}

\author{
Vasant Matsagar ${ }^{1}$
}

Published online: 16 December 2016

(C) The Institution of Engineers (India) 2016

The 9th biennial Structural Engineering Convention (SEC2014) was hosted by the Department of Civil Engineering at Indian Institute of Technology (IIT) Delhi during Monday, 22nd to Wednesday, 24th December 2014. The event formed an excellent platform to attract a diverse range of civil and structural engineering practitioners, academicians, research scholars, and industry delegates to deliberate on the matters concerning structural engineering. It covered a wide range of structural engineering topics such as advanced structural materials, blast resistant design of structures, computational solid mechanics, concrete materials and structures, earthquake engineering, fire engineering, random vibrations, smart materials and structures, soil-structure interaction, steel structures, structural dynamics, structural health monitoring, structural stability, wind engineering, to name a few. A total of 374 full-length papers were accepted for presentation and included in the five-volume book proceedings of the SEC2014, and amongst these 205 papers were included in the book proceedings published by the Springer after a thorough three-stage review and meticulous editing processes. The articles were organised into three volumes in some broad categories covering subject matters on mechanics, dynamics, and materials.

For the ever increasing need of housing and infrastructure with exponential population growth, especially in the seismic prone areas, the need to build earthquake resistant structures for making hazard resilient community cannot be

Vasant Matsagar

matsagar@civil.iitd.ac.in

1 Department of Civil Engineering, Indian Institute of Technology Delhi, Hauz Khas, New Delhi 110 016, India overemphasised. Therefore, the specialised theme of Earthquake Engineering and Structural Dynamics has become of paramount importance especially to the structural engineers. The prime objective of the researchers engaged in developing solutions on variety of earthquake engineering problems has always been to emphasise reducing the seismic vulnerability of structures and thereby ascertaining life safety. Significant research contributions have been made over a quarter of the last century, in the developed as well as developing countries addressing the local and site-specific needs in earthquake resistant design of structures. Based on the sound principles of structural dynamics underlying, the discipline of earthquake engineering subsequently encompasses myriad issues pertaining to the practice of earthquake hazards mitigation, preparedness, and recovery.

With an intention to edify the theoretical and practical aspects of the recent technological advancements made in the disciplines of structural dynamics and earthquake engineering, a two-day International Workshop on "Emerging Trends in Earthquake Engineering and Structural Dynamics" was organised during Saturday, 20th to Sunday, 21st December, 2014 as a preconvention event to the SEC2014 at IIT Delhi. The essential aspects of dynamics and seismic engineering, important for research and industrial applications, were covered in this workshop. This included deliberations on the state-of-the-art of earthquake engineering practices in India, concepts of seismic design in buildings, bridges, pipelines, dams, etc., engineering aspects of seismic micro-zonation, reliability analysis and the advanced topics, such as, seismic control techniques, probabilistic structural dynamics, and structural health monitoring. The main objective of this workshop was to provide a glimpse of emerging trends in the field of 
structural dynamics and earthquake engineering, and to provide an enabling platform for participating delegates to interact with the eminent researchers in these fields in India.

As the protection of civil infrastructure from extreme natural hazards is an important issue, significant efforts are being made worldwide to solve the problems closely related to earthquake engineering and structural dynamics. The growing challenges, which the humanity are facing to mitigate the earthquake hazards and to develop hazard resilient environment, are required to be met with by innovative technologies. With this mission, the organisers of the SEC2014 and the Editors of the Journal of The Institution of Engineers (India): Series-A had decided to undertake the immense task of publishing a Special Issue on "Earthquake Engineering and Structural Dynamics". The outcome of their valuable efforts has been meant to form a rational balance of exchange of know-hows between the academicians and practicing engineers so that both the groups are mutually benefitted. Therefore, eight best papers were invited by a SEC2014 Committee for considerably enhancing the technical matter presented within it for further re-review by the peers and possible publication after acceptance in this Special Issue.

The objectives of publishing this Special Issue in the Journal of The Institution of Engineers (India): Series-A are to highlight the current research trends in earthquake engineering, and to report the scientific contributions made therein focusing on newly constructed steel, reinforced concrete (RC), and composite structures, retrofitting and upgrading issues of the existing structures. The current issue covers a wide range of topics, in terms of analysis and design, experimental testing, and retrofitting of structural assemblage exposed to the dynamic earthquake loads primarily dealing with the safety of the structures. After peerreview process, six articles were finally recommended for publishing in the Special Issue, which generally dealt with the special retrofitting techniques along with the implementation of the novel passive and semi-active control systems in the steel and RC structures. Careful attention was also given on the experimental portion of the articles, which would benefit the practicing design engineers in analysing the customary structures subjected to the earthquake loading. The accepted papers have authorships from different recognised institutes in India; the specific technical details of the accepted papers are given in the following sections.

The Special Issue reports one manuscript concerning findings from the experimental investigation and five manuscripts dealt with the numerical simulation results. The experimental investigation being reported by BharathiPriya and Gopalakrishnan has focussed mainly on mechanically characterising the semi-active vibration control device, magnetorheological (MR) damper with varying strokes. The practicing design engineers will have significant interest in the parameters derived for the MR dampers to be applied in the Bouc-Wen model when used in the earthquake resistant design of newly constructed structures.

An appraisal of the overstrength and ductility factors in the steel moment resisting frame (SMRF) is deemed necessary in the Indian standard (IS) 1893 (Part 1): Criteria for Earthquake Resistant Design of Structures. Accordingly, Rao and Gupta studied the effects of the seismic zone factor $(Z)$ and storey height on the response reduction factor $(R)$ for building systems based on the variations in the overstrength factor and ductility reduction factor. Several buildings designed in accordance with the IS codes experienced damage during the Bhuj earthquake in 2001, attributed to deficient construction practices. These damaged buildings demanded suitable retrofitting and rehabilitation techniques to improve their seismic performance while ascertaining them being code-compliant. By developing site-specific synthetic digital earthquake ground motion records, Kamatchi et al. discussed the performance of the RC buildings at Ahmadabad in Gujarat when passive control devices, viscoelastic dampers, are fitted.

Seismic vibration response of structures is reduced by employing dynamic response control devices, which has been dealt with in the next three research articles. The seismic performance of the RC structures is improved by using the X-plate metallic dampers made of steel and aluminium materials. Manchalwar and Bakre presented optimisation achieved through Genetic Algorithm (GA), how these dampers can be spatially placed in a structure to minimise the cost without hampering the effectiveness in seismic response reduction. Furthermore, the damage induced in the building frames under the earthquakes may also be reduced alternatively by using friction dampers. Nevertheless, studying the nonlinear seismic response of the moment resisting frame (MRF) equipped with the friction damper is important in the performance-based seismic design (PBSD) philosophy, which has been reported by Banerjee and Patro. They related the structural damage imparted due to the earthquakes especially to the dynamic properties of the damper. Finally, by using the advanced tuned liquid damper (TLD) with sloped bottom, enhanced seismic response mitigation in the buildings can be achieved. Patil and Singh presented in their article that if the tuning of frequencies of the TLD and the structure installed with it is achieved then the seismic response could be reduced up to about $60 \%$.

Thus, it is evident that these six research papers have contributed significantly in advancing the state-of-the-art knowledge in earthquake engineering and structural dynamics. We are delighted, therefore, that the broader 
aspects of their contributions reported in these research articles will be beneficial to the wider spectrum of readers in the construction industry and stakeholders such as, the planners, developers, architects, structural designers as well as policymakers and local authorities. The impact of intimate scholarly deliberations during the SEC2014 are now being realised through publication of this Special Issue on Earthquake Engineering and Structural Dynamics in the Journal of The Institution of Engineers (India): Series-A.

Acknowledgements As Organising Secretary of the SEC2014 and the Guest Editor for the Special Issue on Earthquake Engineering and Structural Dynamics, I offer my sincere gratitude to the invaluable support extended by the Editor-in-Chief, Professor Sriman K. Bhattacharyya, the Associate Editor, Professor Subrata Chakraborty, and Dr. Surojit Ghosh, the Assistant Director (Technical) of the Journal of The Institution of Engineers (India): Series-A. Their meticulous efforts have helped tremendously in identifying quality papers in association with the SEC2014 Committee, conducting the peer-review, revising, and publishing in this Special Issue in a timely manner. The distinguished researchers who have scrupulously reviewed all the papers and provided constructive comments for improving quality of the technical presentation are gratefully acknowledged.

Dr. Vasant Matsagar is currently serving as an Associate Professor in the Department of Civil Engineering at Indian Institute of Technology (IIT) Delhi. He obtained his doctorate degree from IIT Bombay in 2005 in the area of earthquake engineering for his $\mathrm{PhD}$ Thesis titled "Earthquake Behaviour and Impact Response Control of Base-Isolated Buildings" from which he is awarded with the "IIT Bombay Research Paper Award". He performed post-doctoral research at the Lawrence Technological University (LTU), Michigan in USA in the area of carbon fibre reinforced polymers (CFRP) in bridge structures for more than three years. His current research interests include structural dynamics and vibration control; multihazard protection of structures from earthquake, blast, fire, and wind; finite element methods; fibre reinforced polymers (FRP) in prestressed concrete structures; and bridge engineering. Dr. Matsagar has guided several students at both undergraduate (UG) and postgraduate (PG) levels in their bachelors and masters projects as well as in doctoral and post-doctoral research. Besides student guidance, he is actively engaged in conducting sponsored research and consultancy projects at the national and international levels. He has published around sixty international journal papers, hundreds of international conference manuscripts, a book, two book chapters, six edited proceedings, and has filed for two patents. He is also involved in teaching courses in structural engineering, e.g. structural dynamics, earthquake engineering, blast resistant design of structures, finite element methods, numerical methods, structural stability, structural analysis, design of steel, reinforced and prestressed concrete structures, to name a few. Apart from organising the Structural Engineering Convention (SEC2014) at IIT Delhi, he has organised several short- and long-term courses as quality improvement programme (QIP) and continuing education programme (CEP), and delivered invited lectures in different educational and research organisations. Dr. Matsagar is the recipient of numerous national and international awards including "Erasmus Mundus Award"; "DST Young Scientist Award" by the Department of Science and Technology (DST); "DAAD Award" by the Deutscher Akademischer Austausch Dienst (DAAD); "DAE Young Scientist Award" by the Department of Atomic Energy (DAE); "IBC Award for Excellence in Built Environment" by the Indian Buildings Congress (IBC); "IEI Young Engineer Award" by the Institution of Engineers (India); and "Outstanding Young Faculty Fellowship" by the Indian Institute of Technology (IIT) Delhi. He has also been appointed as "DAAD Research Ambassador" by the German Academic Exchange Programme since 2010 . He is currently serving on the National Building Code (NBC) development committees in the Bureau of Indian Standards (BIS). 